\title{
EL PARTICIPIO DE PRESENTE EN ARAGONÉS MEDIEVAL
}

\begin{abstract}
Resumen. El participio de presente con valor verbal desaparece en lenguas románicas como el portugués y el español, si bien persiste en francés, occitano y catalán. Su mantenimiento se ha atribuido a la coalescencia con el gerundio como resultado de la apócope extrema. En aragonés medieval el participio de presente aparece con valor predicativo en textos jurídicos, históricos y literarios, aunque en algunas variedades formalmente se diferencia del gerundio. Su empleo ha de ser considerado como un calco culto semejante al que se documenta en castellano. Sin embargo, su uso difiere en ambas lenguas: además de la mayor frecuencia, en aragonés aparece con formas apocopadas y es recogido por gramáticos aragoneses, lo que revela una mayor aceptación y generalización.
\end{abstract}

Palabras clave: participio, aragonés, calco, cultismo.

\section{Introducción}

En los estudios sobre el contacto lingüístico, se ha prestado poca atención a las transferencias lingüísticas que se producen entre lenguas de gran proximidad y entre las que existen relaciones culturales constantes y persistentes. Este sería el caso de los contactos del aragonés con respecto a lenguas como el catalán, el occitano o el francés, con las que comparte una base común y en las que existen evoluciones paralelas y relaciones continuas.

Un aspecto singular de este tipo de contacto es en la incorporación de elementos que tiene lugar cuando una de las lenguas ha desarrollado con anticipación modelos de mayor peso cultural (Baumgarten y Özçetin, 2008). Es lo que sucede en el influjo sobre el aragonés medieval de las lenguas vecinas, catalán, occitano, francés, que habían creado patrones de lengua escrita de gran relieve, a partir de los cuales se producen

\footnotetext{
* Universidad de Valladolid.
} 
transferencias en traducciones y adaptaciones de textos. En tales contactos, sobre los que discute el peso y la naturaleza de las transferencias (Heine, Kuteva, 2005: 250-251), el léxico es lo más copiado por la lengua de destino, pero también hay que considerar los préstamos gramaticales. En este marco teórico podemos examinar el empleo del participio de presente en aragonés medieval.

\section{Resultados románicos del participio de presente}

En latín, el participio de presente, forma adjetival en cuanto a su morfología pero verbal en su significado, se utilizaba en la formulación de una acción referida a un sustantivo con el que concuerda. En cuanto a la localización temporal, señalaba esencialmente concomitancia con la acción del verbo finito al que se subordina: «Sp. Maelium nouis rebus studentem, manu sua occidit» (Cicerón, Catilinarias, I, 3, 'Mató con su propia mano a $\mathrm{Sp}$. Melio, que procuraba nuevas cosas').

Sin embargo, ya en latín, el participio de presente presentaba un deslizamiento hacia el pasado, de manera que se hallaba próximo al participio de pasado: «id quidem agitans mecum sedulo inueni, opinor, remedium huic rei» (Terencio, Phormio, 4, 3, 10, 'también yo pensando y cavilando sobre lo mismo, encontré, creo, el remedio a esta situación').

$\mathrm{Si}$ el participio se refiere a procesos que no tienen un desarrollo temporal limitado sino persistente, tal proceso se puede proponer como una propiedad y entonces se refuerza el valor adjetival referido al SN que aparece como soporte del proceso designado por el participio (obediente $=$ 'el que obedece'), pero sin que se acepten necesariamente otros argumentos en relación a ese proceso. Este hecho suponía que el participio de presente tenía cada vez menos valor verbal (Bassols de Climent, 1956: $\S 387$; Hofmann y Szantyr 1965: 383-384), de manera que otras formas verbales, el infinitivo y el gerundio, asumen parte de sus funciones. En varias lenguas romances, en castellano y en portugués, el participio de presente tiene únicamente esta función adjetival y pierde, por tanto, la capacidad de formar construcciones predicativas.

El participio de presente con función verbal, que permite que junto al SN adyacente aparezca otro SN que remite a un argumento diferente, persiste en francés, occitano y catalán. En francés y en occitano existe apócope extrema, de manera que el gerundio confluye fonética y funcionalmente con las formas del participio de presente, con la única diferencia de que este puede presentar flexión de género y número 
(aman $(t), a m a n z)$ y concuerda con el sustantivo al que se refiere (Töbler, 1902: I, 36-37; Togeby, 1974: 192-193; Jensen, 1986: 250-252; Fernández González, 1985: 362):

(1a) Ce fu li premiers rois de la tiere tenans, les tieres entor lui furent a lui tenans (Roman de Alixandre, 75, 8, apud Töbler, 1902: 45).

(1b) amb vii. m. cavalhers volens aussirre Karle (Pseudo Turpin 485, 21; apud Jensen, 1986: 254).

(1c) je ne sçay quel plaisir vous avez prins voyans les lyons (Rabelais, 2, 308, apud Meyer Lübke, [1890-1905] 1974: III, 559).

(1d) 'aime la bouche imitante la rose (Ronsard, apud Togeby, 1974: 192).

Es posible, no obstante, que estos participios predicativos no sean patrimoniales, sino resultado de una imitación tardía (siglos XV y XVI) del latín (Meyer Lübke, [1890-1905] 1974: III, 559) .

En catalán, igualmente, el gerundio latino amando y el participio activo en singular, amantem, en virtud de la evolución fonética, vinieron a coincidir en la forma amant (Badia i Margarit, [1951] 1981:351). Es también como resultado de esa coincidencia como se interpreta el uso del participio de presente ya en textos catalanes muy antiguos (Bastardas Parera, 1953: 176): «Facta carta donacionis VI kal. dec. a. $X^{\circ}$ Cristo recnantem, regem expectantem» (apud Bastardas Parera, 1953: 176). En textos medievales más recientes, cabe señalar que en las obras de Bernat Metge aparecen doce ejemplos sin concordancia, considerados por Par gerundios, y cuarenta y cinco concordantes, que supone son participios, aunque el citado autor no se atreve a defender que estos últimos sean patrimoniales en catalán (Par, 1923: 311):

(2a) els antichs suplint los desfalliments d'aquells (Bernat Metge 1736, apud Par, 1923: 308).

(2b) E molts, confiants en aço porien caure en la fossa (Bernat Metge 1312, apud Par, 1923: 309).

\section{El participio de presente en aragonés}

El aragonés presenta una situación más compleja, pues existen diferencias notables entre las variedades lingüísticas de los valles pirenaicos y la del Valle del Ebro y, además, hay una variedad especial

${ }^{1}$ Jensen (1986: 250) señala que no es fácil determinar en los empleos en occitano si se trata de gerundios o de participios. Pero describe lo que denomina gerundios flexivos (1986: 254), que considera resultado de la confusión entre gerundio y participio. 
reflejada en la lengua escrita que utilizan la cancillería y textos jurídicos y literarios (Lagüéns Gracia, 1999: 183-185; Enguita Utrilla y Lagüens Gracia, 2004: 65-68). Las distintas variedades aragonesas incorporan desde el latín participios de presente con función adjetiva. Algunos de estos participios son patrimoniales, tenient, semblant, romanient, entrant, otros introducidos posteriormente y claramente cultos, impugnant, ardient, obedient, resplandescient, excelent, etc. En todos estos casos la función atributiva es la misma que se da en castellano y el participio puede, incluso, ser modificado en cuanto al grado $(3 \mathrm{~b}, 3 \mathrm{c}) \mathrm{o}$, como cualquier adjetivo, admitir construcciones preposicionales (3d) y también ser sustantivado (3f):

(3a) et es perezoso ansi como el honso, et es preçioso et amado como el elefant, et es vil et loco como el asno, et es obedient et humil como el pago. (Juan Fernández de Heredia, De secreto secretorum, ed. Juan Manuel Cacho, Zaragoza, Universidad de Zaragoza, 2003, fol. 309r, CORDE).

(3b) empero que Dios sabie bien que de su tornada era el mucho desplazient, et le pesaua de coraçon, (Gestas del rey don Jayme de Aragon, ed. R. Foulché-Delbosc, Madrid, Bibliófilos Madrileños, 1909, pág. 320, CORDE).

(3c) Onde aquella muyt florient ciudat de los lacedemonios que la hora tanto cobdiciaua auer el imperio et senyoria de todo Orient apenas pudo nunca auer en ella cient viellos (Juan Fernández de Heredia, Traducción de la Historia contra paganos, de Orosio, ed. Juan Manuel Cacho, Zaragoza, Universidad de Zaragoza, 2003, fol. 73r, CORDE).

(3d) Aquel guarda el medio que es alegre del bien que sdeujene alos buenos e que no es desplazient del mal que sdeujene alos malos (Libro del Tesoro. Catedral de Gerona, ed. de Dawn Prince, Madison, Hispanic Seminary of Medieval Studies, 1990, fol.81v., CORDE).

(3e) E otros tantos pechen quantos assi... en concejo fazientes o consintientes aurán estado (El Fuero Teruel, ed. de Max Gorosch, Stockhlom, Uppsala, Almqvist \& Wiksells, 1950, pág. 338).

(3f) Donquas, iuditio es dubdoso razonamiento de las personas de los pleitos, en el quoal iuditio son establidos el demandador o el seguient, el deffendedor assí como fuyent, el parescedor assí como seruient et ministrant (Vidal Mayor, ed. de Gunnar Tilander, Lund: Hakan Ohlssons Boktryckeri, 1956, pág. 142).

\section{El participio de presente con valor verbal en aragonés}

En aragonés medieval, se encuentra, además, el participio con valor verbal. Tiene claramente ese pleno valor verbal cuando, juntamente con un sujeto animado, con el que concuerda en número, se construye con otro $\mathrm{SN}$ en función de objeto directo: 
(4a) nunqua çessaua de aprender, no contrastant los treballos de las qu'el hauie (Juan Fernández de Heredia, Grant Crónica de Espanya, ed. de Regina Af Geijerstam, Uppsala, Almqvist \& Wiksells, 1966, pág. 223).

(4b) E en el segundo anyo del regno de Remiro rey, $C$ naues de los normandios ujdientes las dissensiones de los godos, entraron en Gallicia (Obra sacada de las crónicas de San Isidoro, de Don Lucas, Obispo de Tuy, ed. de Juan Manuel Cacho Blecua, Zaragoza, Universidad de Zaragoza, 2003 fol 85r, CORDE).

(4c) D'on nota que can es bestia muyt fiel, amant la salud de su senyor (Juan Fernández de Heredia, Libro de Actoridades (Rams de flors), ed. de Juan Manuel Cacho Blecua. Zaragoza: Universidad de Zaragoza, 2003, fol.. 257r, CORDE).

(4d) Si alguno trobare en so ujnna o en so canpo semnado o en so uuerto laurado o plantado mulo o mula o asno o asna o yegua fazientes danno, deue dar (Los Fueros de Aragón, ed. de Gunnar Tilander, Lund, CWK Gleerup, 1937, pág. 76).

También sucede que el objeto directo es un infinitivo $(5 a, 5 b)$ que, en tal caso, queda subordinado, o incluso puede llegar a introducir un fragmento de enunciado en estilo directo (5c):

(5a) el qual abuso cobdiciantes del todo extirpar por el present edicto prohibimos perpetualment negocios o actos algunos (Ordinación dada a la ciudad de Zaragoza por el rey don Fernando I (el de Antequera), 1414, ed. de Manuel Mora Gaudó, Zaragoza, Impr. Mariano Escar, 1908, pág. 380).

(5b) Por esto querientes proueyr et remediar á todas é cada hunas cosas sobreditas de condecent remedio por el beneficio e buen stamiento e pascifico de la dita Cyudat et de los singulares de aquellya (Adiciones a las Ordinaciones de Barbastro [Ordinaciones y paramientos de la ciudad de Barbastro], Revista de Aragón, 1902-1904, pág. IV, 291 CORDE).

(5c) Juras por la santa iura que iuró el Sennor ad Abraham en el mont de Moria e por la tierra de promission e por Iherusalem e por la cáthedra ondrada de Dios e por los ángeles ministrantes ante el Sennor benedito e por las santas ruedas de los animales stantes cara a cara delant Dios, laudantes e dizientes: "Santo, Santo, Santo... (Los Fueros de Aragón, ed. de Gunnar Tilander, Lund, CWK Gleerup, 1937, pág. 68).

El sujeto del participio de presente puede ser como en 4a, 4b, 4c, 5a, 5b, el mismo de la oración principal, pero igualmente puede ser cualquier otro constituyente de la oración, como en $4 \mathrm{~d}, 5 \mathrm{c}$, e incluso otro constituyente no integrado en la oración principal. En este caso, la construcción con participio funciona como una cláusula adverbial equivalente a las construcciones absolutas del latín:

(6a) E el regno, el qual Tu atorgant, recebi e lo he regido tanto como ha plazido a Tu cata que te lo riendo (Obra sacada de las crónicas de San Isidoro, de Don Lucas, Obispo de Tuy, ed. de Juan Manuel Cacho Blecua, Zaragoza, Universidad de Zaragoza, 2003 fol 85r, CORDE).

(6b) hauje fecha ayuda con grant multitut de huest, al qual ixient a carrera Rucciaro, rey de los sueuos, con grant copia a XII milleros de la ciudat de Astoricensis, cerca el rio qui es clamado Vrbico. (Obra sacada de las crónicas de San Isidoro, de Don 
Lucas, Obispo de Tuy, ed. de Juan Manuel Cacho Blecua, Zaragoza, Universidad de Zaragoza, 2003 fol 48r, CORDE).

(6c) E stant con la reyna Sancia, ujno mesage que Açeyfa, con grant huest de moros, cuytadament ujnje en Castiella (Obra sacada de las crónicas de San Isidoro, de Don Lucas, Obispo de Tuy, fol 83r, Juan Manuel Cacho Blecua, Zaragoza, Universidad de Zaragoza, 2003).

A partir de construcciones absolutas como las citadas, la construcción con participio de prsente llega a fijarse en fórmulas legales que son frecuentes en documentos notariales (Enguita y Lagüens Gracia, 2004: 82):

(6d) Data en Valencia III dias entrant el mes de Março en el anyo de nuestro seynor de MCCC e XIII annos. (Respuesta de Jaime II a la carta de Don Juan Manuel comunicándole que ha detenido al Maestre d..., ed. de Andrés Giménez Soler, Zaragoza, Tip. La Academia, 1932. CORDE).

\section{El participio de presente como calco}

El primer problema que se plantea en relación con estas construcciones 294 participiales es si son patrimoniales o, por el contrario, transferencias de las lenguas vecinas, occitano, catalán o francés. Este es un problema habitual cuando se estudian los posibles préstamos en el aragonés (Pottier, [1955] 1991: 236-238) y la posible solución, como en el caso de las influencias fonéticas o morfológicas, consiste en examinar si el fenómeno en cuestión se vincula con otros factores con los que se asocia habitualmente: en el supuesto que nos ocupa, con la coalescencia de participio con gerundio.

En aragonés medieval existía apócope extrema, no solo de -e sino también de -o finales, al igual que en francés, catalán u occitano, apócope que persiste, incluso hasta la actualidad en ribargozano (Gramática básica de l'aragonés, 2017: 206) y ello podría haber producido la coalescencia entre gerundio y participio. En el Valle del Ebro, la apócope de -o pasa a ser también claramente superior a la conservación de la vocal cuando se lleva a cabo la repoblación, según Alvar (1953: 60). Y es que ese territorio recibe un importante contingente de franceses y de occitanos, tal como se refleja en la antoponimia conservada en los documentos (García Mouton, 1980), lo que, sin duda, debió de tener consecuencias lingüísticas. Sin embargo, hay que tener en cuenta que en aragonés pirenaico el participio de presente se diferencia del gerundio, no solo porque el primero admite la moción de número, sino también porque muchos gerundios se forman analógicamente a partir del tema de perfecto (dixiendo, toviendo, andidiendo) 
(Umphrey, 1913: 35; Alvar, 1953: 225)2. Este hecho sugiere que, a pesar de la apócope extrema, no rara en el Valle del Ebro, a diferencia de lo que sucede en francés y en catalán, en aragonés, al menos en las hablas de los Pirineos, no se debió de producir inicialmente una identificación formal generalizada entre gerundio y participio de presente. Incluso en los textos que proceden de la cancillería aragonesa o en las obras jurídicas y literarias, en los que se emplea abundantemene el participio de presente predicativo, los gerundios están bien diferenciados ${ }^{3}$.

De acuerdo con lo anterior, si no hay coalescencia generalizada con el gerundio, el uso del participio activo con valor verbal en los textos medievales aragoneses habría de ser considerado, al menos en parte, como un calco. Sucede, además, que tales empleos predicativos del participio se dan predominantemente en ciertos géneros discursivos, en textos jurídicos, históricos o literarios, que se elaboran estrechamente vinculados a traducciones y adaptaciones a partir de obras de otras lenguas románicas vecinas (occitano, catalán, francés) o a partir del latín, lo cual corroboraría la hipótesis del calco.

\section{Rasgos específicos de los calcos de participio en aragonés}

Si el empleo verbal del participio de presente en aragonés es un calco, el hecho de que aparezca en textos cultos, debería hacernos sospechar que puede ser un calco del latín. También en castellano el participio de presente en construcción verbal aparece con cierta frecuencia en textos literarios latinizantes de los siglos XIV o XV (Pons Rodríguez, 2005). No obstante, en castellano, la incorporación del participio de presente se documenta sobre todo para referirse a cualidades. Así, se recoge en la poesía del Marqués de Santillana, de Juan de Mena o de Francisco Imperial, entre otros ${ }^{4}$ :

${ }^{2}$ Hanssen ([1896] 1980: 408) recoge igualmente la diferencia entre el gerundio, ffallando, frente al participio, regnant.

3 Por ejemplo, en Los Fueros de Aragón, se documentan aueniendo, constreniendo, diziendo, exiendo, faziendo, fuyendo, podiendo, queriendo, recebiendo, seguiendo, trayendo, uediendo, ueniendo, etc.

${ }^{4}$ Keniston (1937: 552) encuentra algunos ejemplos en el siglo XVI. Cita dos casos de construcción absoluta en el primer cuarto de siglo y otros tres de participio de presente con función adjetiva. 
(7a) Desque sentida la su proporçion / de humana fortuna non ser discrepante / el mjedo pospuesto persigo adelante (Juan de Mena, Laberinto de fortuna, ed. de John G. Cummins, Madrid: Cátedra, 1979, pág. 65).

(7b) Era en el primero, teniente en la diestra / La foz incurvada, el grand Cultivante (Marqués de Santillana, Comedieta de Ponça, ed. de Maxim P. A. M. Kerkhof, Madrid: Cátedra, 1986, pág. 111).

(7c) El ángel de paz sea su guardante / e lo guarde siempre de toda ocasión (Francisco Imperial, Cancioneo de Baena, ed. de Brian Dutton y Joaquín González cuenca, Madrid, Visor Libros, 1993, pág. 275).

La diferencia más importante con el aragonés radica en el hecho de que, en castellano, estos usos no afectan al paradigma verbal en el que el gerundio es una forma bien caracterizada. Los gramáticos castellanos recogen estos empleos: Nebrija en la Gramática Castellana, cuando alude a formas de participio de presente, precisa tanto su origen culto, como su uso adjetival: «el castellano apenas siente el participio del presente i del venidero, aunque algunos delos varones doctos introduxieron del latín algunos dellos como doliente, paciente, bastante, sirviente, semejante, corriente, venidero, passadero, hazedero, amadero...» (Nebrija, [1492] 1946: 80, 130). A Juan de Valdés los participios con empleo adjetival tampoco le resultan apropiados: «No me plaze dezir durmiente, por el que duerme 296 mucho, como dize el refrán: Al raposo durmiente no le amanece la gallina en el vientre» (Valdés, [1535?] 1965: 109).

Por otra parte, el participio de presente se emplea con valor verbal en obras castellanas fuertemente influidas por el catalán, tal como sucede en las traducciones que realiza el llamado marqués de Villena:

(8a) Es de montañias áspera, es a saber purgativa e provocante a fazer áspera emienda (Enrique de Villena, Traducción y glosas de la Eneida. Libros I-III, ed. de Pedro M. Cátedra, Madrid, Turner Libros, 1994, pág. 612, CORDE).

(8b) comia e desmenbrava a los querientes entrar (Enrique de Villena, Los doze trabajos de Hércules, ed. de Margherita Morreale, Madrid, Real Academia Española, 1958, pág. 49).

En estos textos en castellano, los calcos, evidentes, quedan desvinculados de la posible coalescencia entre gerundio y participio ${ }^{5}$. Mientras que en los calcos del aragonés, el participio está habitualmente apocopado, en los castellanos el participio aparece sin apócope y, de acuerdo con la evolución general del castellano, aparece la vocal final, tanto en el gerundio (fuyendo, apartando, catando) como en el participio

${ }^{5}$ En italiano antiguo el uso verbal del participio de presente es considerado igualmente como un calco del latín. En algunos casos, podría ser también un calco del francés o un mero error de transcripción (Salvi y Renzi, 2010: II, 898-899). Los usos más recientes del italiano han sido vistos también como calcos (Wandruszka, 1958). 
de presente (querientes, enbargante, leyentes) (Ridruejo, 1984). En las Coronaciones de Pedro IV, transmitidas por Jerónimo de Blancas en 1585, en castellano, pero respetando «el mismo lenguage antigo», es decir, aragonés, es abundante el participio de presente con valor verbal, e igualmente sus formas aparecen sin apócope (considerantes, estantes, querientes, respondientes, veyentes) (Lagüéns Gracia, 2009: 39). Ello revela una cierta castellanización.

\section{La aceptación del participio predicativo en aragonés}

Si en la gramática castellana de fines del siglo XV y del XVI no se recomiendan los participios de presente incorporados como cultismos, incluso los meramente adjetivos, en cambio, en obras gramaticales aragonesas se aceptan estos participios, también con valor verbal. Encontramos su presencia ya en el manuscrito 153 de Ripoll, redactado probablemente en el reinado de Pedro IV (por tanto, antes de 1387) (Esparza Torres y Calvo Fernández, 2008) ${ }^{6}$ y en el Perutile Grammaticale Conpendium de Daniel Sisó, publicado en 1490, probablemente en Zaragoza en la imprenta de Pedro Hurus. Ambas obras se inscriben en la corriente de las denominadas grammaticae proverbiandi (Esparza Torres y Calvo Fernández, 2001) y, como es habitual en tales tratados, recurren a la lengua vulgar como elemento de apoyo para la enseñanza del latín.

En el manuscrito 153 de Ripoll aparece el participio de presente al tratar de la «reciprocatio» con ejemplos como Pedro, amant se de Maria y Pedro amant de Maria. (Esparza Torres y Calvo Fernández, 2008: 69). En la gramática de Sisó se emplea extensamente esta forma para mostrar equivalencias textuales entre latín y romance (Ridruejo 1997). Ese autor establece las siguientes correspondencias del latín con el romance:

Participio de presente amans - amant

Participio de pretérito amatus - amado

Participio de futuro amaturus o amandus - amadero

(Sisó, 1490: f. 28 v. y ss.)

${ }^{6}$ El manuscrito alude a la lengua romance que está empleando con el nombre «lengua de los aragoneses»: Octavo, nota in quo cognoscuntur in romancio nomina verbalia terminata in '-or' vel in '-trix', dico quod secundum linguam Aragonensium cognoscuntur in hoc: quod si termine $<\mathrm{n}>$ tur in '-dor', tunc erunt verbalia terminata in '-tor', sed <si $>$ romancia terminentur in '-dera' vel in '-trix', tunc erunt nomina verbalia terminata in '-trix' (f. 92r., Esparza Torres y Calvo Fernández, 2008: 47). 
En la traducción al romance de los ejemplos latinos, el participio de presente se construye claramente como verbo que rige un objeto directo: «Petrus amans Mariam venit componitur Pedro amant a María viene; Petrus legens lectionem venit componitur Pedro leyent la lection viene» (Sisó, 1490: f. 29). Además, en el apartado denominado de las suplencias del participio se incluyen contrucciones participiales romances que no tienen contrapartida en otros participios del latín y, en esta lengua, en general, equivalen a oraciones de relativo:

El iusticia sterrant el ladrón viene componitur iustitia a quo exulat latro venit. El maestro leydo la lición viene componitur magister que legit lectionem venit. La lición leyent del mestro es provechosa componitur lectio quae legitur a magistro es commodosa (Sisó, 1490: f. 42).

Estos usos del participio de presente aparecen siempre en su forma apocopada, y ello puede explicarse por ser la más más próxima al latín, pero también por el origen de Sisó, quien era de Fraga, en la franja catalanoahablante de Aragón, donde las formas apocopadas debían de ser comunes, o incluso como características del aragonés literario.

\section{Conclusiones}

En aragonés, como en castellano o en portugués, siguiendo la deriva iniciada en latín clásico, el participio de presente tiende a quedar reducido a empleos adjetivales. Sin embargo, en los géneros discursivos más dependientes de la influencia del occitano, del francés, del catalán o del latín, se incorporan construcciones verbales de participio de presente. Se trata de calcos cultos, consecuencia de un tipo de contacto que afecta a las variedades históricas, jurídicas o literarias. En los calcos gramaticales, como el que describimos, nos encontramos, de acuerdo con la caracterización que hacen Thomason y Kaufman (1988: 74-76), con transferencias del significado de unidades gramaticales existentes en otra lengua, de suerte que una forma, ya preexistente en la lengua receptora, modifica su significado y, por ende, tanto sus relaciones en el paradigma en que se integra, como las reglas sintácticas con que se construye hasta que se acomodan a la producción de las unidades o construcciones tranferidas.

Estos calcos se presentan también en castellano pero la diferencia con el aragonés radica en que en la última lengua las transferencias fueron facilitadas por la existencia de contactos más antiguos y constantes. En aragonés, al menos en parte del dominio, tenía lugar apócope extrema y, 
con ella, la coalescencia entre el participio de presente en singular con muchos gerundios, de manera que refuerza la construcción verbal, hasta el punto de que aparece reflejada en textos gramaticales.

\section{Bibliografía}

ALVAR, M. (1953). El dialecto aragonés. Madrid: Gredos.

BADIA I MARGARIT, A. ([1951] 1981). Gramàtica històrica catalana, Valencia: Tres i Quatre.

BASSOLS DE CLIMENT, M. (1956). Sintaxis latina. Madrid: CSIC.

BASTARDAS PARERA, J. (1953). Particularidades sintácticas del latín medieval (cartularios españoles de los siglos VIII al XII). Barcelona: Escuela de Filología.

BAUMGARTEN, N. y ÖZÇETIN, D. (2008). «Linguistic variation through language contact in translation», en P. SIEMUND y N. KINTANA (eds.), Language Contact and Contact Languages. Amsterdam / Philadelphia: John Benjamins, 293-316.

CORDE - Real Academia Española, Corpus diacrónico del español [en línea] <http:// corpus.rae.es/cordenet.html>, fecha de consulta: abril de 2018.

ENGUITA UTRILLA, J. M. y LAGÜÉNS GRACIA, V. (2004). «En torno a los orígenes del romance aragonés», Aemilianense. Revista Internacional sobre la génesis y los orígenes históricos de las lenguas romances, 1, 65-93.

ESPARZA TORRES, M. A. y CALVO FERNÁNDEZ, V. (2001). «La gramática proverbiandi y la Nova Ratio Nebrissensis», en K. KOERNER y H.-J. NIEDEREHE (eds.), History of Linguistics in Spain II. Amsterdam / Philadelphia: John Benjamins Publishing Company, 35-56.

ESPARZA TORRES, M. A. y CALVO FERNÁNDEZ, V. (2008). «Las notas en aragonés del manuscrito gramatical 153 Ripoll», Gramma-Temas 3: España y Portugal en la tradición gramatical, 43-73.

FERNÁNDEZ GONZÁLEZ, J. R. (1985). Gramática histórica provenzal. Oviedo: Universidad de Oviedo.

GARCÍA MOUTON, P. (1980). «Los franceses en Aragón (siglos XI-XIII)», Archivo de Filología Aragonesa, XVI-XVII, 7-98.

GRAMÁTICA BÁSICA DE L'ARAGONÉS (2017). (Texto provisional). EDACAR (Edicions Dichitals de l'Academia de l'Aragonés), Estudio de Filolochia Aragonesa, 10.

HANSSEN, F. ([1896] 1980). «Estudios sobre la conjugación aragonesa», Archivo de Filología Aragonesa, XVI-XVII, 401-418.

HOFMANN, J. B. y SZANTYR, A. (1965). Lateinische Syntax und Stilistik, Munchen: C. H. Beck.

HEINE, B. y KUTEVA, T. (2005). Language Contact and Grammatical Change. Cambridge: Cambridge University Press.

JENSEN, F. (1986). The Syntax of Medieval Occitan. Tübingen: Max Niemeyer. 
KENISTON, H. (1937). The Syntax of Castilian Prose. The Sixteenith Century. Chicago: The University of Chicago Press.

LAGÜÉNS GRACIA, V. (1999). «El aragonés medieval. Estado de la cuestión», en J. M. ENGUITA (ed.), Jornadas de Filología Aragonesa en el L aniversario del AFA, 2 vols. Zaragoza: Institución Fernando el Católico, II, 163-264.

LAGÜÉNS GRACIA, V. (2009). "Contactos lingüísticos y transmisión textual a propósito del léxico de las Coronaciones glosado por Jerónimo de Blancas, I», AFA, 65: 33-96.

MEYER LÜBKE, W. ([1890-1905] 1974). Grammaire des langues romanes (4 vols.). Géneve / Marseille: Slatkine Reprints / Laffitte Reprints.

NEBRIJA, A. de ([1492] 1946). Gramática Castellana. Edición crítica de Pascual Galindo Romeo y Luis Ortiz Muñoz. Madrid: Edición de la Junta del Centenario.

PAR, A. (1923). Sintaxi catalana segons los escrits en prosa de Bernat Metge (1398). Halle: Max Niemeyer.

PONS RODRÍGUEZ, L. (2005). La historia de las formas no personales del verbo en español. Liceus. Edición informática.

POTTIER, B. (1947). «Notas de sintaxis en las gestas de don Jayme el Conquistador. Miscelánea aragonesa», 3, Archivo de Filología Aragonesa, 2, 119.

POTTIER, B. ([1955] 1991). «Elementos gascones y languedocianos en el aragonés medieval», Archivo de Filología Aragonesa, 46-47, 235-244.

RIDRUEJO, E. (1984). «Tres catalanismos (y aragonesismos) sintácticos en los Doze Trabajos de Hércules del Marqués de Villena», Archivo de Filología Aragonesa. Homenaje a Tomás Buesa, 34-35, 273-290.

RIDRUEJO, E. (1997). «Lengua real y artefactos lingüísticos: sobre el romance de Daniel Sisó», en R. ESCAVY ZAMORA y otros (eds.), Homenaje al Profesor Antonio Roldán Pérez, vol. II. Murcia: Universidad de Murcia, 511-522.

SALVI, G. y RENZI, L. (2010). Grammatica dell'italiano antico. Bologna: Il Mulino.

THOMASON, S. G. y KAUFMAN, T. (1988). Language contact, creolization, and genetic linguistics. Berkeley: University of California Press.

TÖBLER, A. (1902). Vermischte Beiträge zur Französischen Grammatik. Erste Reihe. Leipzig: Verlag von S. Hirzel.

TOGEBY, K. (1974). Précis historique de grammaire française. Odense: Akademisk Forlag.

UMPHREY, G. W. (1913). The aragonese dialect. New York-Paris: Macon Protat Freres.

VALDÉS DE, J. ([1535?] 1964). Diálogo de la lengua. Edición y notas por J. F. MONTESINOS. Madrid: Espasa-Calpe.

WANDRUSZKA, M. (1958). «Neubelebung des Partizipiums auf -ante, -ente, -iente», en H. LAUSBERG (ed.), Romanica, Festschrift für Gerhard Rohlfs. Halle: Max Niemeyer, 478-484. 